\title{
Point-of-Use Water Treatment and Use among Mothers in Malawi
}

\section{Lauren J. Stockman, ${ }^{*} \dagger$ Thea K. Fischer,* Michael Deming, ${ }^{*}$ Bagrey Ngwira, $\ddagger$ Cameron Bowie, $\ddagger$ Nigel Cunliffe, $\S$ Joseph Bresee, ${ }^{*}$ and Robert E. Quick*}

A national household survey was conducted in Malawi to determine awareness and use of a socially marketed water treatment product. In all, $64 \%$ of mothers were aware of the product, and $7 \%$ were using it. Both poor and rural mothers had lower awareness and use rates. Targeting promotion to rural populations could enhance program effectiveness.

$\mathrm{D}$ iarrhea is a leading cause of childhood deaths in the developing world (1), where many people rely on drinking water that is contaminated with pathogens. To address this problem, the Centers for Disease Control and Prevention (CDC) and the Pan American Health Organization/World Health Organization developed the Safe Water System (SWS), which consists of water treatment at the point of use with a locally produced, dilute sodium hypochlorite solution, safe water storage, and behavior change techniques such as social marketing (2). The SWS has been shown to decrease diarrhea risk by $25 \%-85 \%(3-7)$ and has been implemented in $>25$ countries.

In November 2002, an SWS social marketing program was initiated in Malawi to prevent diarrheal illness among children $<5$ years of age, who were found to have a prevalence of diarrhea of $18 \%$ during a 2 -week period in the 2000 Malawi Demographic and Health Survey (8). The SWS was promoted through radio announcements, flyers, signs on walls and minibuses, and billboards. The disinfectant solution, which was branded as WaterGuard, cost 10 kwacha (approximately \$US 0.08) for sufficient solution to treat stored water for 1 month and was sold in small plastic bottles at supermarkets, pharmacies, and by street vendors.

In April 2005, CDC and the University of Malawi conducted a national household survey on healthcare, utilization patterns, and costs of childhood diarrhea and pneumonia in Malawi. We took the opportunity to mea-

${ }^{*}$ Centers for Disease Control and Prevention, Atlanta, Georgia, USA; †Atlanta Research and Education Foundation, Decatur, Georgia, USA; łUniversity of Malawi College of Medicine, Blantyre, Malawi; and §University of Liverpool, Liverpool, UK sure mothers' awareness, perception, and reported use of WaterGuard.

\section{The Study}

This survey used the "modified segment" design described in the United Nation Children's Fund's End-Decade Multiple-Indicator Survey Handbook (9), which resulted in an equal-probability sample of 3,000 households in 30 enumeration areas throughout the country. All mothers of children $<5$ years of age were interviewed. Data were analyzed with SAS-callable SUDAAN 9.0.1 PROC RLOGIST (SAS Institute, Inc., Cary, NC, USA). Multivariate regression models were used to determine predictors of WaterGuard awareness and use. Colinearity and interactions between variables were assessed. To create an indicator of socioeconomic status, household asset factor scores, generated from a principal components analysis from the Malawi 1992 Demographic and Health Survey, were calculated by using the method described by Gwatkin et al. (10).

Among 3,000 households included in the survey, 1,787 mothers (or maternal caretakers) were identified, of whom $1,669(93 \%)$ were eligible, having at least 1 child $<5$ years; all completed the survey. This sample was representative of the population distribution for Malawi, according to the Malawi 2004 Demographic and Health Survey (Table 1).

Among 1,669 mothers, 1,075 (64\%; 95\% confidence interval [CI] 58-71) had heard of WaterGuard; of these $726(68 \%)$ believed the product was "to make water safe," $230(21 \%)$ believed the product was "to prevent diarrhea," and $108(10 \%)$ either did not know or gave another answer. Among the mothers who had heard of WaterGuard, 556 (52\%) said they had used it "at some point in the past," and $124(12 \%)$ reported that they were currently using it. Current users represented 7\% (95\% CI 4-11) of the total population. Among these, 77 (62\%) said that WaterGuard caused "less diarrhea," or "less illness in the family." Rates of awareness and use of the product were higher among those living in an urban area than a rural area. Among 432 mothers who had used WaterGuard in the past, but were not using it at the time of the survey, 168 (39\%) indicated that they "cannot afford it," 145 (34\%) that it was "currently unavailable," 12 (3\%) that they "don't like the taste," and 1 said she didn't "think it makes water safer." In all, $106(25 \%)$ gave no reason for no longer using WaterGuard. In a multivariate model, WaterGuard awareness was independently associated with living in an urban area (adjusted odds ratio [aOR] $3.92 \mathrm{p}<0.001)$, being a mother who had attended school (aOR 2.84, $<<0.001$ ), having a husband who had attended school (aOR 1.90, $\mathrm{p}<0.001)$, and higher wealth quintile (aOR $1.97 \mathrm{p}=0.0003$ ) (Table 2). Current use of WaterGuard was independently associated with living in an urban residence compared to a rural residence $(\mathrm{aOR}=2.01, \mathrm{p}=0.0342)$ (Table 2$)$. The program budget 
Table 1. Household description of mothers/caretakers interviewed and 2004 Malawi Demographic and Health Survey (DHS) data for comparison

\begin{tabular}{lccc}
\hline & \multicolumn{2}{c}{2005 Household survey } & 2004 Malawi DHS, \% \\
\cline { 2 - 3 } Variable & No. (\%) & $95 \% \mathrm{Cl}^{*}$ & 13 \\
\hline Region & $211(13)$ & $4-34$ & 41 \\
$\quad$ North & $725(44)$ & $26-63$ & 46 \\
$\quad$ Central & $716(43)$ & $26-63$ & 18 \\
$\quad$ South & $156(9)$ & $3-27$ & 82 \\
Population & $1,489(91)$ & $73-97$ & 79 \\
$\quad$ Urban & $1,290(79)$ & $75-87$ & 16 \\
$\quad$ Rural & $289(18)$ & $13-25$ & \\
Latrine & $1,117(67)$ & $53-79$ & 36 \\
$\quad$ Traditional pit toilet & $539(32)$ & $21-47$ & 36 \\
$\quad$ No facility & & & \\
$\quad$ Drinking water & & \\
$\quad$ Unimproved source & & \\
\hline${ }^{*}$ Cl, confidence interval. & & \\
\hline
\end{tabular}

and national WaterGuard sales in Malawi were substantially lower than comparable data from a similar SWS program in Zambia (Figure).

\section{Conclusions}

This national survey of Malawian mothers found awareness of WaterGuard to be high in a very poor country with limited commercial penetration into rural areas. In addition, over half of mothers who had heard of WaterGuard had tried it, and $12 \%$ of these mothers reported currently using the product at the time of the survey. Figures for awareness and past use in the present survey were consistent with an SWS survey conducted in Zambia (11), a country that borders Malawi and has a similar poverty and development ranking (12). However, reported current use of SWS in Zambia was, at $42 \%$, substantially higher than in Malawi, reflecting substantially higher product sales in Zambia. Unlike the program in Malawi, which has had inconsistent and relatively low levels of funding, the SWS program in Zambia has had stable funding at a higher level and substantially greater sales. If the Malawi SWS program were able to obtain stable funding at higher levels, similar utilization rates to those in Zambia might be attainable.

A substantial gap exists between the percentage of mothers aware of WaterGuard who had tried it and those who were current users at the time of the survey $(52 \%$ vs.

\begin{tabular}{|c|c|c|c|c|c|}
\hline Predictor variable & Total & No. $(\%)$ & Crude OR $(95 \% \mathrm{CI}) \dagger \ddagger$ & Adjusted OR $(95 \% \mathrm{Cl}) \S$ & $p$ value \\
\hline \multicolumn{6}{|l|}{ Have heard of WaterGuard } \\
\hline Urban population & 156 & $147(94.2)$ & $9.87(5.46-17.85)$ & $3.92(2.26-6.78)$ & $<0.001$ \\
\hline Mother attended school & 909 & $713(78.4)$ & $3.75(2.59-5.42)$ & $2.84(2.00-4.05)$ & $<0.001$ \\
\hline Husband attended school & 1,072 & $776(72.4)$ & $2.89(2.22-3.78)$ & $1.90(1.45-2.49)$ & $<0.001$ \\
\hline Higher wealth quintile & 608 & $471(77.5)$ & $2.54(1.69-3.80)$ & $1.97(1.41-2.74)$ & 0.0003 \\
\hline \multicolumn{6}{|l|}{ Region } \\
\hline Central & 723 & $461(63.8)$ & $1.15(0.47-2.80)$ & NS & \\
\hline South & 708 & $484(68.4)$ & $1.41(0.63-3.14)$ & NS & \\
\hline Mother employed & 74 & $59(79.7)$ & $2.15(1.03-4.50)$ & NS & \\
\hline Improved drinking water & 1,106 & $718(64.9)$ & $0.95(0.61-1.47)$ & NS & \\
\hline \multicolumn{6}{|l|}{ Currently using WaterGuard } \\
\hline Urban population & 144 & $34(23.6)$ & $2.86(1.55-5.28)$ & $2.01(1.06-3.82)$ & 0.0342 \\
\hline \multicolumn{6}{|l|}{ Region } \\
\hline Central & 456 & $67(14.7)$ & $3.36(1.60-7.05)$ & $1.88(0.93-3.78)$ & 0.1981 \\
\hline South & 481 & $50(10.4)$ & $2.26(0.96-5.31)$ & $1.49(0.60-3.70)$ & 0.1981 \\
\hline Mother employed & 58 & $13(22.4)$ & $2.22(1.06-4.67)$ & $1.67(0.83-3.39)$ & 0.1465 \\
\hline Higher wealth quintile & 465 & $72(15.5)$ & $1.87(1.08-3.23)$ & $1.42(0.84-2.42)$ & 0.1866 \\
\hline Mother attended school & 709 & $91(12.8)$ & $1.45(0.69-3.01)$ & NS & \\
\hline Husband attended school & 771 & $93(12.1)$ & $1.22(0.67-2.21)$ & NS & \\
\hline Improved drinking water & 712 & $87(12.2)$ & $1.22(0.46-3.21)$ & NS & \\
\hline
\end{tabular}

*OR, odds ratio; $\mathrm{Cl}$, confidence interval; NS, variable did not meet criterion for remaining in the multivariate model. TOR $>1$ for region central or region south indicates a higher probability than the north region.

¥OR $>1$ for higher quintile ( 4 and 5 ) indicates a higher probability than those in the lower quintile $(1,2$, and 3 ).

$\S$ Predictor variables with a $p=0.10$ in univariate analysis were included in the multivariate model to adjust for these simultaneously.

Ip value for Wald F statistic for the adjusted OR. 


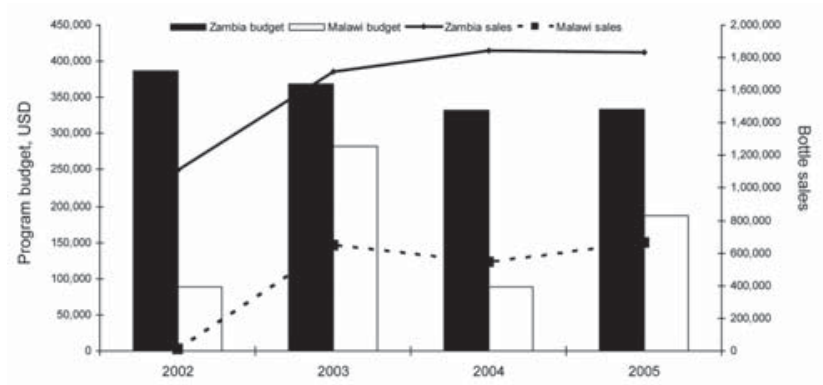

Figure. Annual program budget and product sales of Safe Water System programs in Malawi and Zambia, 2002-2005. Year 2005 total population: Zambia, 11,502,010; Malawi, 13,013,926 (www.cia. gov/cia/publications/factbook/geos/za.html). Budget and sales data provided by Population Services International. USD, US dollars.

$12 \%$, respectively), which can be considered a dropout rate of $78 \%$. The goal of SWS in Malawi is to increase water quality in an area with limited access to clean water; therefore, sustained use among mothers is as important for long-term health effects as is increasing the initial use of the intervention. The reasons given by mothers who stopped using WaterGuard suggest that cost was a primary barrier to sustained use, especially among rural mothers. More research is needed to better define these and other reasons for discontinuation of water treatment to better inform efforts to increase WaterGuard availability and affordability. The positive perception of WaterGuard among those currently using it, together with the product's proven ability to disinfect water and prevent diarrhea, justifies continued efforts to market and evaluate the cost effectiveness of WaterGuard in Malawi (13).

Overall, findings of this survey support a need to increase WaterGuard promotion and distribution among poorer, less educated, and rural populations. Social marketing programs typically have difficulty reaching rural populations because of inadequate rural commercial infrastructure (11). If commercial mechanisms are not sufficient to promote rural use, then alternative, nontraditional approaches should be considered. For example, a program that used trained nurses in a maternal and child health clinic to promote SWS was associated with an increased rate of SWS use in rural Kenya (14), and use of motivational interviewing has resulted in higher purchase and usage rates of water disinfectant in Zambia (15). Using women's groups to market and sell products as income-generating activities, may also be efficacious (www.who.int/household_water/ resources/freeman.pdf). We recommend that such marketing efforts be targeted to mothers who are least aware of the product and who could benefit the most from safe drinking water, including those who have not attended school, live in a rural area, or are have a lower socioeconomic status.

\section{Acknowledgments}

We are grateful for the field team in Malawi who interviewed participants, Wantwa Mwenchanya, Gloria Banda, Petri Mtenda, Else Mwenechanya, Andrew Ngwira, and field team supervisors Kelias Msyamboza and Peter Nyasulu. We thank Roger Glass for his contribution to this study and Sally Cowal, Chuck Szymanski, and Sarah Romorini for sharing Population Services International program data.

Ms Stockman is an epidemiologist in the National Center for Immunization and Respiratory Diseases, CDC. Her interests include the epidemiology of enteric viruses and community-based public health interventions.

\section{References}

1. Parashar UD, Bresee JS, Glass RI. The global burden of diarrhoeal disease in children. Bull World Health Organ. 2003;81:236.

2. Mintz ED, Reiff FM, Tauxe RV. Safe water treatment and storage in the home. A practical new strategy to prevent waterborne disease. JAMA. 1995;273:948-53.

3. Quick RE, Kimura A, Thevos A, Tembo M, Shamputa I, Hutwagner $\mathrm{L}$, et al. Diarrhea prevention through household-level water disinfection and safe storage in Zambia. Am J Trop Med Hyg. 2002;66: 584-9.

4. Quick RE, Venczel LV, Mintz ED, Soleto L, Aparicio J, Gironaz M, et al. Diarrhoea prevention in Bolivia through point-of-use water treatment and safe storage: a promising new strategy. Epidemiol Infect. 1999; 122:83-90.

5. Semenza JC, Roberts L, Henderson A, Bogan J, Rubin CH. Water distribution system and diarrheal disease transmission: a case study in Uzbekistan. Am J Trop Med Hyg. 1998;59:941-6.

6. Crump JA, Otieno PO, Slutsker L, Keswick BH, Rosen DH, Hoekstra RM, et al. Household based treatment of drinking water with flocculant-disinfectant for preventing diarrhoea in areas with turbid source water in rural western Kenya: cluster randomised controlled trial. BMJ. 2005;331:468-9.

7. Lule JR, Mermin J, Ekwaru JP, Malamba S, Downing R, Ransom $\mathrm{R}$, et al. Effect of home-based water chlorination and safe storage on diarrhea among persons with human immunodeficiency virus in Uganda. Am J Trop Med Hyg. 2005;73:926-33.

8. The 2000 Malawi demographic and health survey report. National Statistical Office of Malawi. ORC Macro; 2001. [cited 2006 Apr 4]. Available from http://www.nso.malawi.net

9. United Nations Children's Fund. End-decade assessment: multiple indicator cluster survey; 2000. [cited 2006 Apr 5]. Available from http://www.childinfo.org/mics2/finman/m2finm.htm

10. Gwatkin D, Rustein S, Johnson K, Pande R, Wagstaff A. Socioeconomic differences in health, nutrition and population in Malawi. [cited 2006 Apr 5]. Available from http://povlibrary.worldbank.org/ library/view/4148

11. Olembo L, Kaona F, Tuba M, Burnman G. Safe water systems: an evaluation of the Zambia CLORIN program. US Agency for International Development through the Environmental Health Project. [cited 2004 Sep 26]. Available from http://www.ehproject.org/pdf/ others/zambia\%20report\%20format.pdf

12. United Nations Development Programme. Human development report 2005. [cited $2006 \mathrm{Apr} 5$ ]. Available from http://hdr.undp.org/reports/global/2005/pdf/hdr05 complete.pdf

13. Hutton G, Haller L. Evaluation of the costs and benefits of water and sanitation improvements at the global level. [cited 2006 Dec 21]. Geneva: World Health Organization; 2004. Available from http:// www.who.int/water_sanitation_health/wsh0404.pdf 
14. Parker AA, Stephenson R, Riley PL, Ombeki S, Komolleh C, Sibley L, et al. Sustained high levels of stored drinking water treatment and retention of hand-washing knowledge in rural Kenyan households following a clinic-based intervention. Epidemiol Infect. 2006;134:1029-36.

All material published in Emerging Infectious Diseases is in the public domain and may be used and reprinted without special permission; proper citation, however, is required.
15. Thevos AK, Kaona FA, Siajunza MT, Quick RE. Adoption of safe water behaviors in Zambia: comparing educational and motivational approaches. Educ Health (Abingdon). 2000;13:366-76.

Address for correspondence: Lauren J. Stockman, Centers for Disease Control and Prevention, 1600 Clifton Rd, Mailstop A34, Atlanta, GA 30333, USA; email: 1stockman@cdc.gov

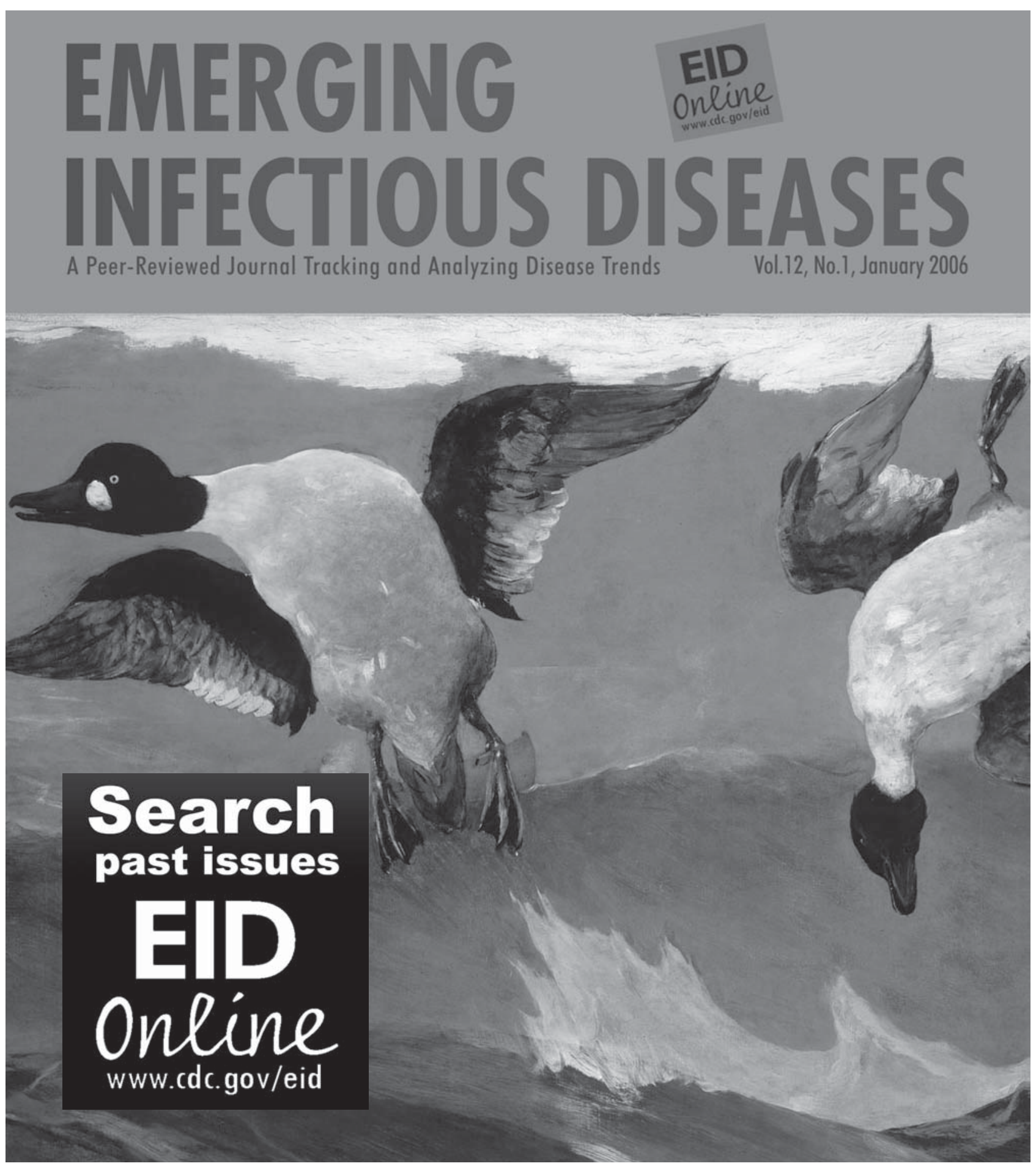

